\title{
Blastomicosis prostática: presentación de un caso y revisión de la literatura
}

\section{Blastomycosis of the prostate: a case report and literature review}

\section{Sr. Director:}

La blastomicosis es una enfermedad micótica endémica, predominantemente de las regiones central sur y medio oeste de los Estados Unidos y de algunas regiones de Canadá1. Esta patología está causada por Balstomices dermatitidis, un organismo dimórfico normalmente adquirido por la inhalación de las esporas. La mayoría de los pacientes afectados en la fase aguda están asintomáticos o llegan a desarrollar sintomatología respiratoria inespecífica que se autolimita. La neumonía crónica es la manifestación clínica predominante de esta patología ${ }^{1}$. La afección extrapulmonar es común y se suele presentar en la piel, el tejido celular subcutáneo, el hueso, las articulaciones y el sistema nervioso central, y se han reportado incluso casos en la glándula prostática y el epidídimo ${ }^{1-3}$.

Realizamos una revisión bibliográfica en busca de casos clínicos reportados de pacientes con afección prostática de esta enfermedad y encontramos un número no superior a los 10 casos, por lo que compartimos un caso clínico de nuestra institución.

Se trata de un varón de 70 años de edad, con antecedente de hipertensión arterial, que consulta por cuadro de retención urinaria aguda, de 6 meses de evolución, caracterizado por la presencia de síntomas de obstrucción urinaria baja, con disminución paulatina de la fuerza y calibre del chorro urinario, pujo premiccional y nicturia de hasta 5 ocasiones, que progresaron hasta caer en retención urinaria aguda.

En la exploración física sólo llamaba la atención la presencia de hiperplasia prostática benigna grado II.

Dentro de sus exámenes paraclínicos destacaba una biometría hemática normal (hemoglobina: 12,9 g/dl; leucocitosis: 5.390; plaquetas: 180.000). La química sanguínea fue normal (BUN: 14,4 mg/dl; Cr: 1,04 mg/dl). El antígeno prostático específico fue de $8,3 \mathrm{ng} / \mathrm{ml}$ y un mes después de $5,3 \mathrm{ng} / \mathrm{ml}$. El ultrasonido en ambos riñones reveló pérdida de la relación corteza-médula de predominio derecho, dilatación ureteral leve bilateral, así como glándula prostática de 60 cc de volumen.

Se realizó biopsia transrectal de próstata, en la que se reporta blastomicosis de la próstata (fig. 1).

Se inicia manejo con itraconazol vía oral y se programa para resección transuretral de próstata, que se realiza tres semanas después, en la que se reporta prostatitis granulomatosa por blastomicosis en el material enviado a Patología.

Dos semanas después el paciente presenta un evento vascular cerebral hemorrágico y fallece por complicaciones del mismo.

La blastomicosis es una enfermedad inusual, cuya transmisión es respiratoria, y de la que se han reportado casos en los que se ha visto involucrado el aparato genitourinario ${ }^{4-6}$.

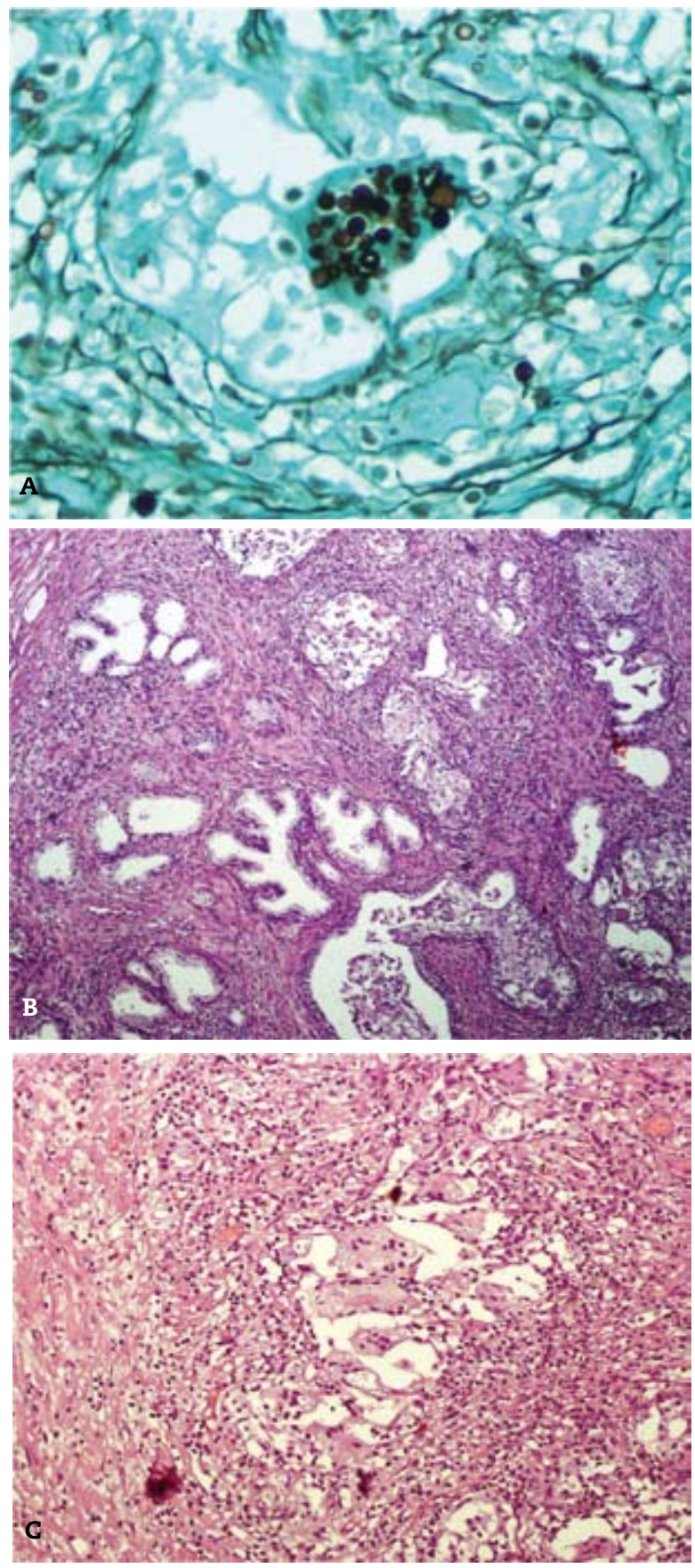

Figura 1 - Cortes histopatológicos en los que se evidencia tinción PAS (A) positiva, Grocott (B) positiva y BAAR (C) negativa, concluyéndose como diagnóstico la presencia de prostatitis granulomatosa por blastomicosis. 
Sus manifestaciones clínicas son inespecíficas, y suelen variar desde manifestaciones respiratorias leves autolimitadas hasta síndrome de distrés respiratorio agudo y/o compromiso del sistema nervioso central ${ }^{1}$. En el caso de nuestro paciente se encontraba básicamente asintomático y acudió por sintomatología prostática secundaria a hiperplasia benigna de la próstata, y el diagnóstico se realizó como hallazgo.

En nuestra revisión sólo en un caso se reporta la afección prostática única ${ }^{4}$, uno con afección prostática y miliar ${ }^{7}$, el resto se reportan acompañados de afección de epidídimo ${ }^{3,6}$ y uno en la piel y la próstata ${ }^{5}$. Existe una revisión realizada por Eickenberg et al en $1975^{2}$ en la que se evaluaron 51 expedientes de pacientes con blastomicosis sistémica en Norteamérica, encontrando de estos a 11 pacientes con afección genitourinaria, siendo el epidídimo y la próstata los más comúnmente afectados.

En lo referente al manejo se recomienda terapia antimicótica oral, sugiriéndose itraconazol como de primera línea, y en casos de síntomas graves y/o paciente inmunocomprometidos el manejo de elección es a base de anfoterisina $\mathrm{B}^{1}$.

Hasta el momento no se conocen medidas preventivas de esta enfermedad, y actualmente se encuentra en estudio una posible vacuna con organismos vivos atenuados ${ }^{1}$.

La blastomicosis es una entidad rara en nuestro medio, de difícil diagnóstico por lo inespecífico de su sintomatología, pero que aparentemente suele tener cierta predilección por la glándula prostática y el epidídimo cuando se encuentra afectado el aparato genitourinario.

Recomendamos tener presente esta entidad, sobre todo en pacientes con síntomas de obstrucción urinaria baja crónicos, diagnosticados de prostatitis crónicas abacterianas, ya que pudiesen existir más casos como este y ser subdiagnosticados, debido a que no se cuenta con ningún screening para los mismos.

Sería interesante buscar intencionalmente esta entidad en las prostatitis crónicas abacterianas, y de esta manera conocer la verdadera incidencia de la misma, ya que existe manejo específico y efectivo para esta patología. Se necesita un estudio controlado y bien estandarizado, y así buscar entidades como esta como la causa de las prostatitis crónicas abacterianas.

\section{B I B L I O G R A F Í A}

1. Pappas PG. Blastomycosis. Semin Respir Crit Care Med. 2004;25(2):113-21.

2. Eickenberg HU, Amin M, Lich R Jr. Blastomycosis of the genitourinary tract. J Urol. 1975;113(5):650-2.

3. Seo R, Oyasu R, Schaeffer A. Blastomycosis of the epididymis and prostate. Urology. 1997;50(6):980-2.

4. Bunge RG, Harness WN. Blastomycosis of the prostate: case report. J Urol. 1951;66(2):263-4.

5. Botvinick I. Blastomycosis of the skin and prostate. AMA Arch Derm Syphilol. 1950;62(6):936-7.

6. Smith PG, Suder GL. Blastomycosis of the epididymis and prostate: a case report. Urol Cutaneous Rev. 1950;54(7):398-9.

7. Burr AH, Huffines TR. Blastomycosis of the prostate with military dissemination treated by stilbamidine. J Urol. 1954;71(4):464-8.

A. García Morúa*, J. D. Gutiérrez García, F. Valdes Sepúlveda, J. F. Lozano Salinas y L.S. Gómez Guerra Servicio de Urología, Hospital Universitario Dr. José E González, Monterrey, Nuevo León, México

${ }^{*}$ Autor para correspondencia Correo electrónico: agmorua@live.com.mx y alejandro.garcia@urologiahu.org.mx

(A. García Morúa) 